\title{
Toxicology, Other
}

National Cancer Institute

\section{Source}

National Cancer Institute. Toxicology, Other. NCI Thesaurus. Code C19454.

This term is used as a form filler when there is no appropriate Toxicology term available. 